\title{
Syntax-Pragmatics interface in converbal constructions
}

Nyurguyana Petrova

University at Buffalo

Converbs are non-finite verb forms which indicate adverbial subordination (Haspelmath 1995). Converbal clauses can occur in chaining constructions, where they are stacked one after the other to advance the narration (Nedjalkov 1995), as in sentence (1) from Sakha.

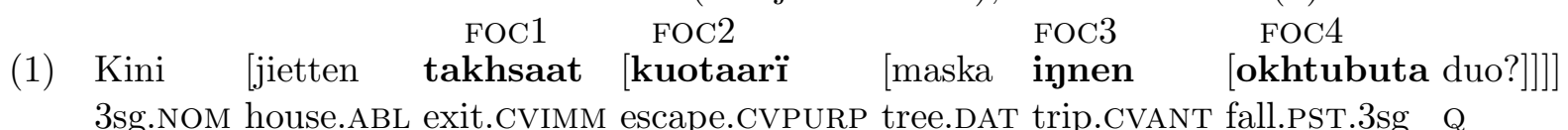

'Did (s)he fall having come out of a house, trying to escape, and having tripped over a tree?'

'Having come out of a house, did (s)he fall trying to escape and having tripped over a tree?'

'Having come out of a house, and trying to escape, did (s)he fall down having tripped over a tree?' 'Having come out of a house, trying to escape, and having tripped over a tree, did (s)he fall down?'

In these constructions the accent that indicates focus determines the scope of the illocutionary force. Since this is an under-recognized typological pattern that occurs in non-European languages, it has not generally been treated in detail formally.

Foley and Van Valin (1984), Van Valin (2005) predict that cosubordination is characterized by shared illocutionary scope. However, Bickel (2010) claims that there are crosslinguistic occurrences of cosubordinate constructions (e.g. Belhare, Nepali), where the scope of the interrogative marker in the main clause is indeterminate: depending on the context, the sentences can be interpreted as having conjunct or disjunct scope. Similarly, the chaining constructions in Sakha show variation in extent of the illocutionary scope of a sentence. According to data and native speakers' judgement, the variation depends on the information-structure of a sentence, i.e. a placement of focus in a sentence. Example (1) has three converbs takhsaat 'exit', kuotaarï 'escape' and innen 'trip' that modify a finite verb okhtubuta 'fall'. The scope of a question operator duo extends up to a verb in focus (FOC) and questions it. When only takhsaat 'exit' is in focus, a whole sentence is questioned. When kuotaarï 'escape' is in focus, the action of someone exiting a house is presupposed. When innen 'trip' is in focus, the action of exiting a house and attempts to escape are presupposed. The fourth interpretation is derived when okhtubuta 'fall' gets focus, in which case all of the actions described by the converbs are presupposed and the action described by the finite verb is questioned.

This study provides a mechanism for capturing the interaction of mood and informationstructure in converbal constructions. There is no formal treatment of this phenomenon to the best of my knowledge. The analysis of the information-structure, couched in HeadDriven Phrase Structure Grammar (HPSG), is drawn from Engdahl and Vallduvi (1996). Although this analysis was meant to capture information structure of English and Catalan sentences, it can, with few modifications, be applied effectively to the Sakha sentences. In Engdahl and Vallduvi (1996), the features FOCUS and GROUND represent new and old information respectively. The latter introduces two other features: LINK (which establishes a particular locus of update in the input information state) and TAIL (which indicates that a non-default mode of update is (in the speaker's eyes) required at the point of discourse). 
Engdahl and Vallduvi (1996) assume that there is a mapping between a word's accent and the information-structure and suggest the constraint given in (2) below:

(2) Accent and Information Structure (IS) lexical constraint:

Every word can either have an ACCENT A (that denotes a high-pitch accent in Sakha) with an information-structure (IS) of FOCUS or it can have an ACCENT B (that denotes a falling accent in Sakha) with an information-structure of GROUND|LINK or it can have an ACCENT 'unmarked' with an information-structure of no value.

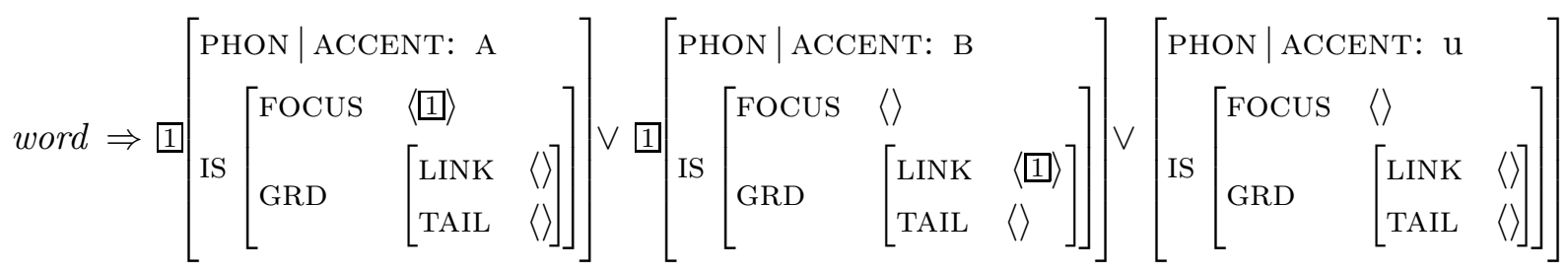

The principle of information-structure assignment, elaborated in (3) below, applies to every node in the syntactic tree. We adopt the contruction-based feature geometry of Sag et al. (2003).

(3) Information Structure (IS) assignment principle:

Either 1) the information-structure of the mother node is the concatenation of the lists of the daughters' information-structure and (if the daughter occurs with focus) the construction assigns tail to the daughters' information-structure excluding the daughters with link; or 2) the information-structure of the mother node is the sign itself if the most oblique (non-head) daughter contains focus.

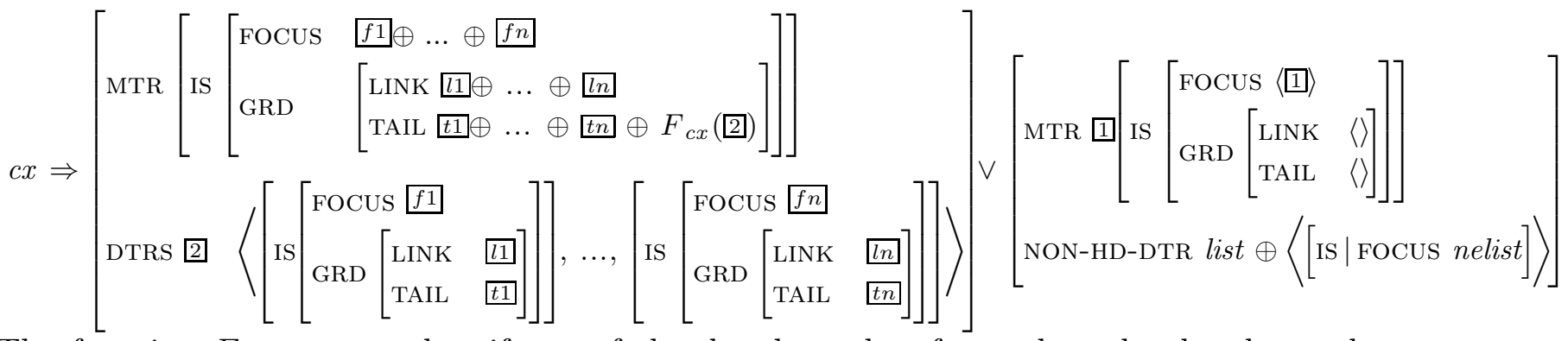

The function $F_{c x}$ ensures that if one of the daughters has focus then the daughters that are unaccented are placed in TAIL exluding the ones with LINK. Otherwise, nothing else is placed in TAIL. Function $F_{c x}$ achieves this by splitting the list of daughters into three sublists, according to their information-structure values, using the shuffle relation (' $\bigcirc$ ') (Reape 1996). The first sublist (which must be non-empty) contains the daughters with foci, the second contains the links, and the third contains the unaccented daughters. The latter list - 1 - is output by $F_{c x}$ and is required to reside in TAIL. If none of the daughters has focus then $F_{c x}$ outputs an empty list.

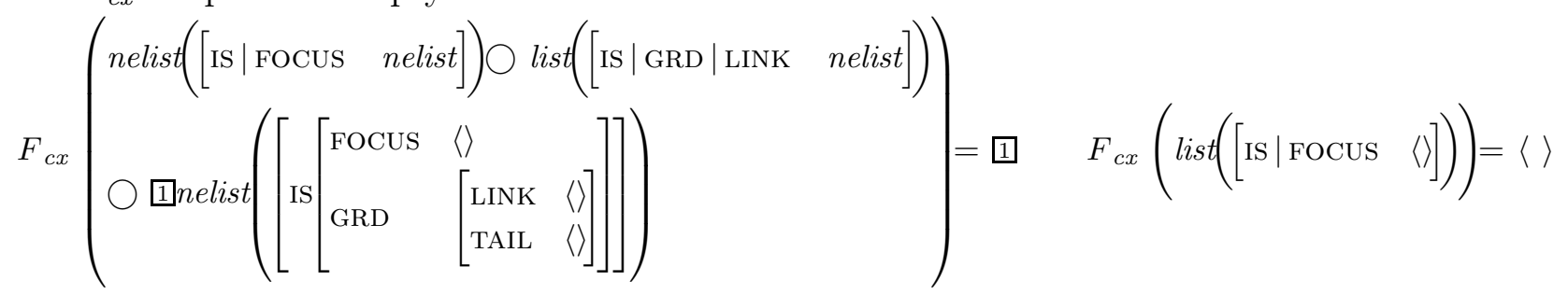

A tree provided in Figure 1 demonstrates an application of the principles discussed above. 


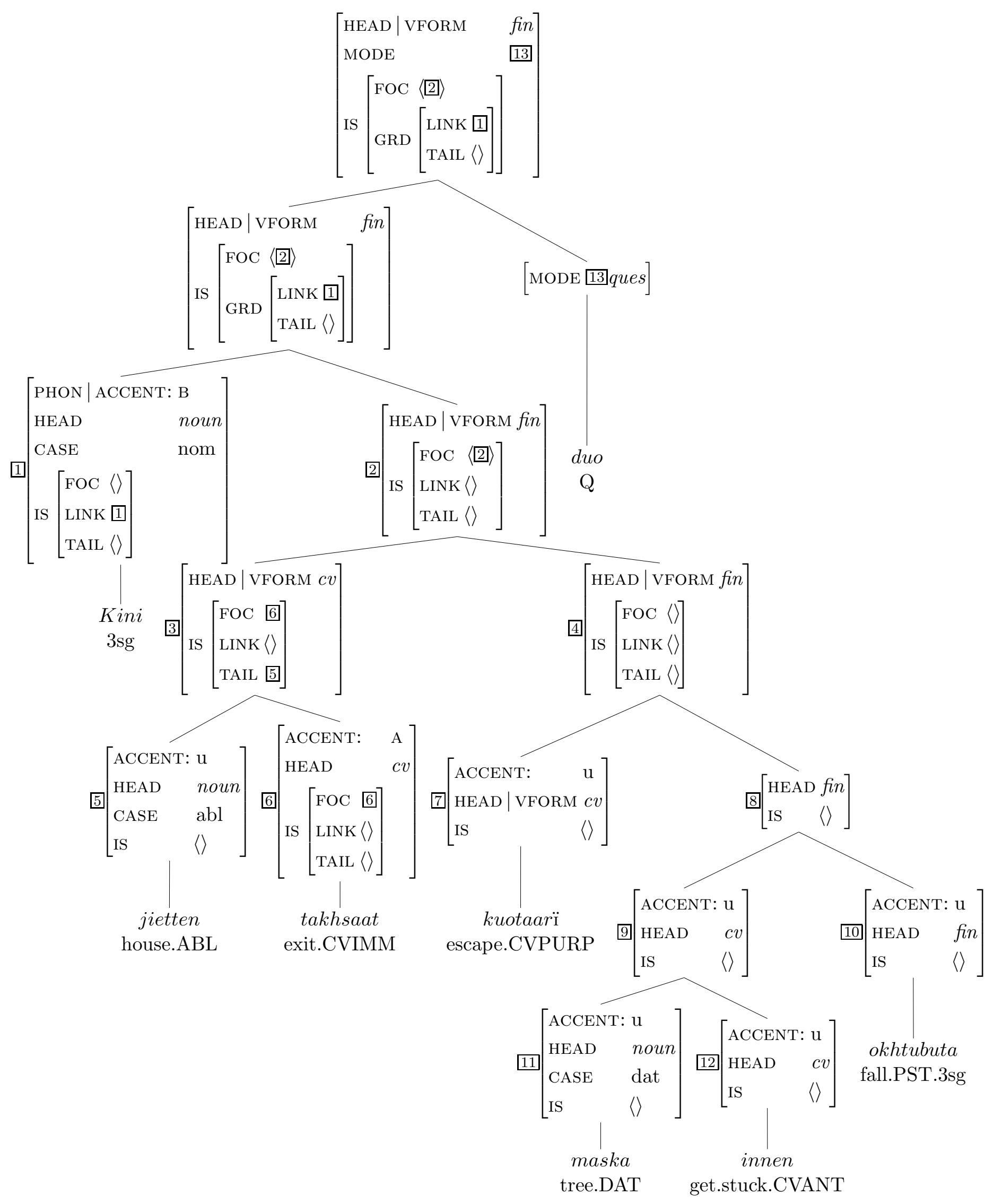

Figure 1: Application of the Information-structure assignment principle 
For example, when the first converb takhsaat 'exit.CVIMM' from sentence (1) is in focus indicated by accent $\mathrm{A}$, the first part of the information-structure assignment principle is applied: the focus in takhsaat 'exit.CVIMM' is propagated to the mother node, while jietten 'home.ABL' becomes tail as a mode of update. Furthermore, since the converbal phrase is not the head daughter but the VP with the finite verb is, the second part of the principle is applied and establishes wide focus in the sentence. The subject kini '3sg.nOM' is a locus of update in the input information state, therefore, it gets assigned link. These rules ensure that the scope of the illocutionary operator extends only as far as a verb in focus and its complements. It also ensures that even though the scope of illocutionary scope may vary, a main clause is always found under the scope of illocutionary scope. These constraints hold in the Sakha chaining constructions with converbs and possibly in various other languages that behave alike. (Note that IS \langle\rangle is used as an abbreviation, to mean that FOC, LINK, and TAIL have empty lists as values.)

This work establishes that chaining constructions in Sakha behave comparably to languages without chaining in terms of focus assignment. Future research will examine whether the interaction of illocutionary force and information-structure holds true for other languages with clause chaining constructions.

\section{Abbreviations}

ABL - ablative case; CVANT - converb of anteriority; CVIMM - converb of immediate-precedence; CVPURP - converb of purpose; DAT - dative case; NOM - nominative case; PST - past; Q question word

\section{References}

Bickel, B. (2010). [in press] Capturing particulars and universals in clause linkage: a multivariate analysis. In I. Bril (Ed.), Clause-hierarchy and clause-linking: the syntax and pragmatics interface. Amsterdam: Benjamins.

Engdahl, E. and E. Vallduvi (1996). Information packaging in HPSG. Working Paper in Cognitive Science 12, 1-32.

Foley, W. and R. Van Valin (1984). Functional Syntax and Universal Grammar. Cambridge: Cambridge University Press.

Haspelmath, M. (1995). The converb as a cross-linguistically valid category. In M. Haspelmath and E. Koenig (Eds.), Converbs in Cross-Linguistic Perspective. Berlin, New York: Mouton de Gruyter.

Nedjalkov, V. (1995). Some typological parameters of converbs. In M. Haspelmath and E. Koenig (Eds.), Converbs in Cross-Linguistic Perspective. Berlin, New York: Mouton de Gruyter.

Reape, M. (1996). Getting things in order. In H. C. Bunt and A. van Horck (Eds.), Discontinuous Constituency, pp. 209 - 254. Netherlands: Walter de Gruyter.

Sag, I. A., T. Wasow, and E. M. Bender (2003). Syntactic theory: A Formal Introduction. Standford, California: Center for the Study of Language and Information.

Van Valin, R. (2005). Exploring the Syntax-Semantics Interface. Cambridge: Cambridge University Press. 